\title{
Consistency of the national realization of dew-point temperature using NIS standard humidity generators
}

\author{
Doaa Abd El-Galil* and M.G. Ahmed \\ National Institute for Standards - NIS, Thermal Metrology Lab, Tersa St., Elharam, El-Giza, P.O. 136, Giza 12211, Egypt
}

Received: 5 January 2016 / Accepted: 9 December 2016

\begin{abstract}
A comparison of two standard humidity generators (two-temperature (2-T) and one-temperature (1-T) generators) that are developed by the National Institute for Standards (NIS) has been performed using a transfer standard chilled-mirror hygrometer and measurement procedures to realize dew-point temperature $T_{\mathrm{d}}$ in the range from $-50{ }^{\circ} \mathrm{C}$ to $0^{\circ} \mathrm{C}$. The main objective of this comparison was to compare the realizations of dew-point temperature and to establish the level of consistency between the two generators. For a level of consistency between two measurements, it is expressed by the difference between the measured values, $m_{1}-m_{2}$, and the expanded pair uncertainty of this difference $U_{\mathrm{p}}$ [1]. The comparison measurements revealed dew-point temperature differences of $0.02^{\circ} \mathrm{C}$ and $0.07^{\circ} \mathrm{C}$ with expanded pair uncertainties of $\pm 0.09{ }^{\circ} \mathrm{C}$ and $\pm 0.15^{\circ} \mathrm{C}$.
\end{abstract}

Keywords: dew-point temperature / humidity / generators / uncertainty

\section{Introduction}

There are several techniques available to generate humidity references by using stream of saturated gas with well-known water-vapor content to be used in calibration of chilled-mirror hygrometers. These techniques such a dew-point generator: generators based upon a so-called two-temperature method, generators based upon a one-temperature method and generators based upon a two-pressure method [2-4]. The Egyptian national humidity standards in the range $-50^{\circ} \mathrm{C}$ to $0{ }^{\circ} \mathrm{C}$ are currently maintained using two standard humidity generators $(1-\mathrm{T})$ and $(2-\mathrm{T})$.

In 2009, a new (1-T) generator was developed and characterized at NIS to extend the dew-point temperature range down to $-50{ }^{\circ} \mathrm{C}$. The main target of developing the (2-T) generator was to improve the measurement uncertainty. These two generators have been developed and characterized at NIS with different saturator designs for primary realization of the dew-point temperature scale. Both of the generators are based on the saturation of a constant flow of air with respect to a plane surface of liquid water at elevated pressure. These generators are capable to operate with common carrier gases such as nitrogen or air at constant pressure. The calibration and measurement capabilities (CMCs) $(k=2)$ for the $(2-\mathrm{T})$ generator are $\pm 0.065{ }^{\circ} \mathrm{C}$ to $\pm 0.0713^{\circ} \mathrm{C}$ in the dew point range from $-50{ }^{\circ} \mathrm{C}$ to $+10^{\circ} \mathrm{C}$ and for the (1-T) generator are $\pm 0.06^{\circ} \mathrm{C}$ to $\pm 0.15^{\circ} \mathrm{C}$ in the dew-point range from $-50^{\circ} \mathrm{C}$ to $0^{\circ} \mathrm{C}$.

\footnotetext{
* Corresponding author: m.dody74@yahoo.com
}

A precision chilled-mirror hygrometer has been used to investigate the level of consistency between the realizations of the two generators in the dew-point temperature range from $-50{ }^{\circ} \mathrm{C}$ to $0^{\circ} \mathrm{C}$ to that comprise the NIS humidity standard [5].

\section{Materials and methods}

\subsection{Standard humidity generators}

\subsubsection{Two-temperature humidity generator (2-T)}

The main generator parts are air compressor, pure air desiccant dryer, pre-cooler heat-exchanger, saturating system (saturator and saturator chamber), two liquid baths, four standard platinum resistance thermometers (SPRTs), two platinum resistance thermometers (Pt-100's) "class A", AC resistance thermometer bridge and a multimeter as shown in Figure 1.

Air was first dried and filtered before entering the generator to avoid any contamination and then it was led into the pre-cooler heat-exchanger which was used to precondition the air before it passes through the saturator inlet tube.

The pre-cooler comprises six parallel stainless-steel tubes, each has $6.4 \mathrm{~mm}$ outer diameter with lengths of $1 \mathrm{~m}$. The dew-point temperature $T_{\mathrm{d}}$ of air was supposed to be the same as the saturator temperature. The saturated air was then entered the copper labyrinthine saturator to improve the thermal contact between the thermostatic bath and the saturator main body which has an internal depth of $40 \mathrm{~mm}$. It was partially filled with distilled water. In this case, the air will be in direct contact with water 


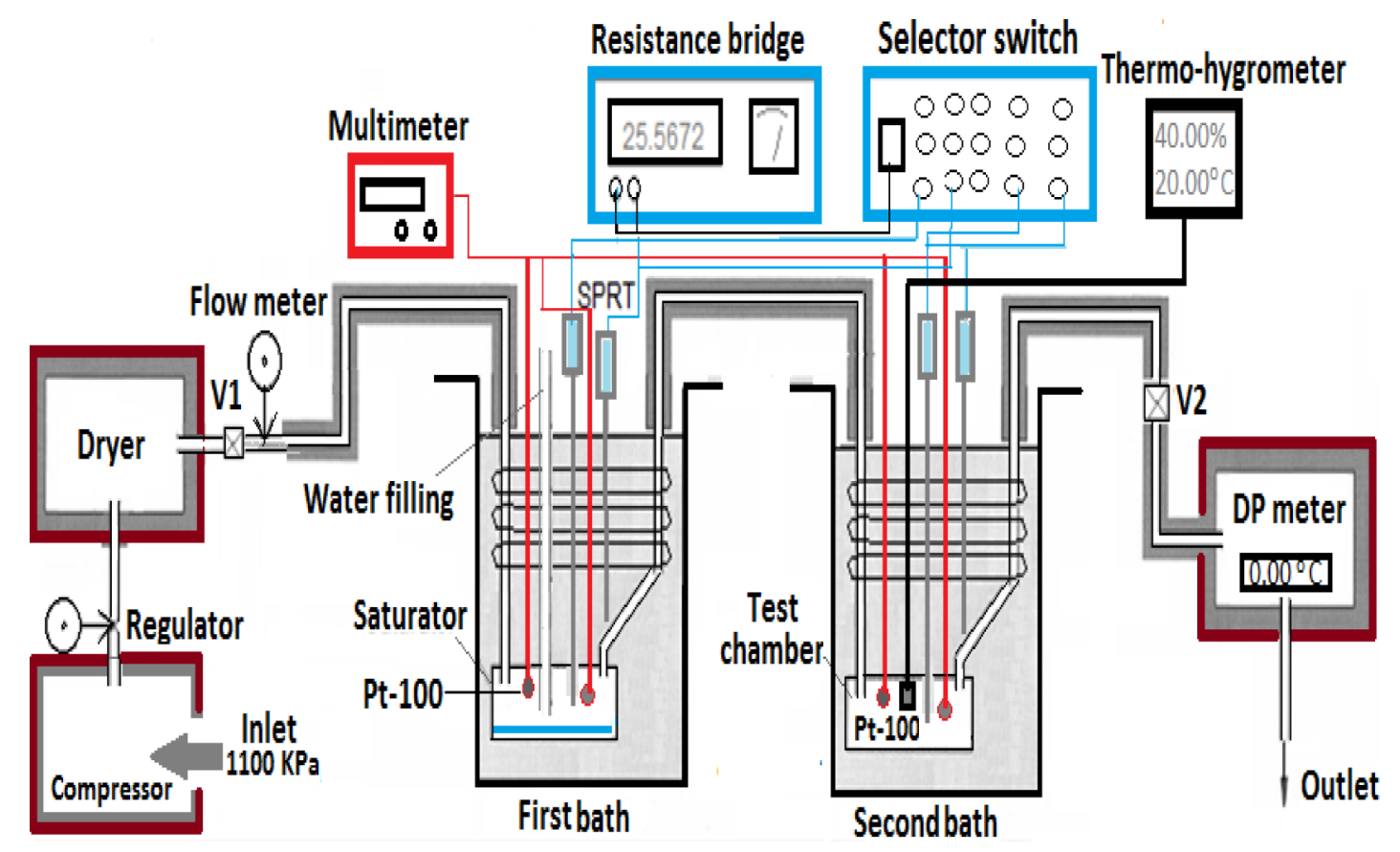

Fig. 1. Schematic diagram of the two-temperature generator.

surface. An additional tube of $6.4 \mathrm{~mm}$ outer diameter with thickness $1 \mathrm{~mm}$ is connected to the saturator outlet to control the water level [6].

After passing this stage, a complete saturation is ensured by forcing the air, at 4 bar, in the saturator chamber. This pressure was chosen as a suitable pressure for the best performance for the dryer as recommended from its manufacturer manual. The saturator chamber is a copper box like a vessel. Saturated air is then drawn off from the saturator chamber through the straight vertical outlet tube. Both saturating system and the coiled-tube heat-exchanger are completely immersed into the liquid baths in a vertical position. The temperature of saturator was determined using one SPRT calibrated according to the international temperature scale 1990 (ITS-90) positioned in the saturator exit. The temperature of the test chamber was measured by another SPRT positioned in the chamber exit. Two Pt-100 thermometers were used to measure the saturator and test chamber temperature gradients.

\subsubsection{One temperature dew-point generator (1-T)}

The principle of the operation is to allow a stream of dry gas, forcing it by air compressor at 4 bar, to flow over a surface of distilled water inside the pre-saturator. This pre-saturator is maintained at ambient temperature as shown in Figure 2. The air-stream will then cooled inside the main saturator. This saturator is designed to be totally immersed in a thermostatic liquid bath. The saturator is a coiled-tube shape that is made of stainless steel with an internal diameter of $5 \mathrm{~mm}$ and length of $1500 \mathrm{~mm}$ [7]. A flow controller valve of the chilled-mirror hygrometer is used to set a suitable flow rate in the range from 20 to $60 \mathrm{l} / \mathrm{h}$. An SPRT, connected to an $\mathrm{AC}$ precision resistance bridge, is placed in the liquid bath to monitor the dew-point temperature.

\subsubsection{Transfer standard}

For the comparison, one chilled-mirror hygrometer "model DP30", manufactured by "MBW", working in the dewpoint temperature range from $-60^{\circ} \mathrm{C}$ to $60^{\circ} \mathrm{C}$ was used. This hygrometer was calibrated at Federal Institute of Metrology (METAS) (Switzerland).

\subsection{Measurements}

Measurements were performed under the following conditions:

The flow rate of the gas at the conditions of the mirror was kept constant at $30 \mathrm{l} / \mathrm{h}$, ambient conditions of the laboratory were a temperature of $23 \pm 2{ }^{\circ} \mathrm{C}$ and a relative humidity of $40-60 \%$ to ensure good performance, and mirror of the hygrometer was cleaned frequently with isopropanol followed by deionized water to reduce the effect of possible contamination.

The measurements were performed as following:

The transfer standard chilled-mirror hygrometer was calibrated firstly using the (1-T) generator at dew-point temperatures from $-50^{\circ} \mathrm{C}$ to $0^{\circ} \mathrm{C}$ every $10^{\circ} \mathrm{C}$ and then it was calibrated using the (2-T) generator at dew-point temperatures from $-50{ }^{\circ} \mathrm{C}$ to $0{ }^{\circ} \mathrm{C}$ every $10^{\circ} \mathrm{C}$.

\section{Results}

The results obtained are depicted in Figure 3. For each generated dew-point the differences $\left(\Delta T_{\mathrm{d}}=T_{\mathrm{d}(1-\mathrm{T})}-T_{\mathrm{d}(2-\mathrm{T})}\right)$ between the transfer standard reading of the (1-T) and the (2-T) generators were calculated and plotted as a function of the dew-point temperature. Measurements of the generators temperature were recorded at the same time of measurements 


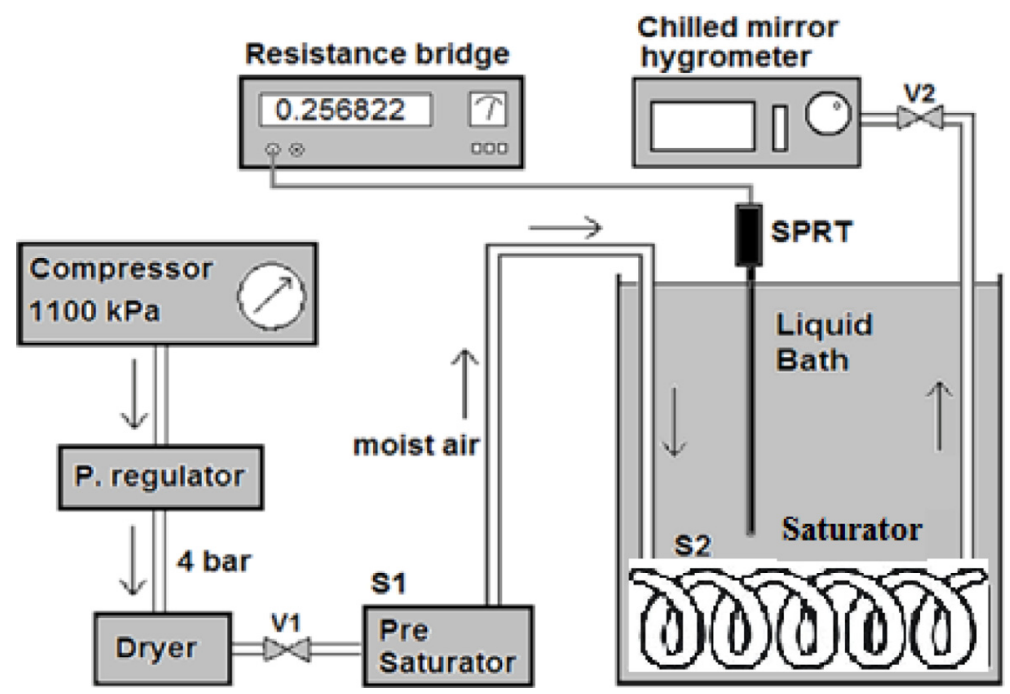

Fig. 2. Schematic diagram of one temperature generator.

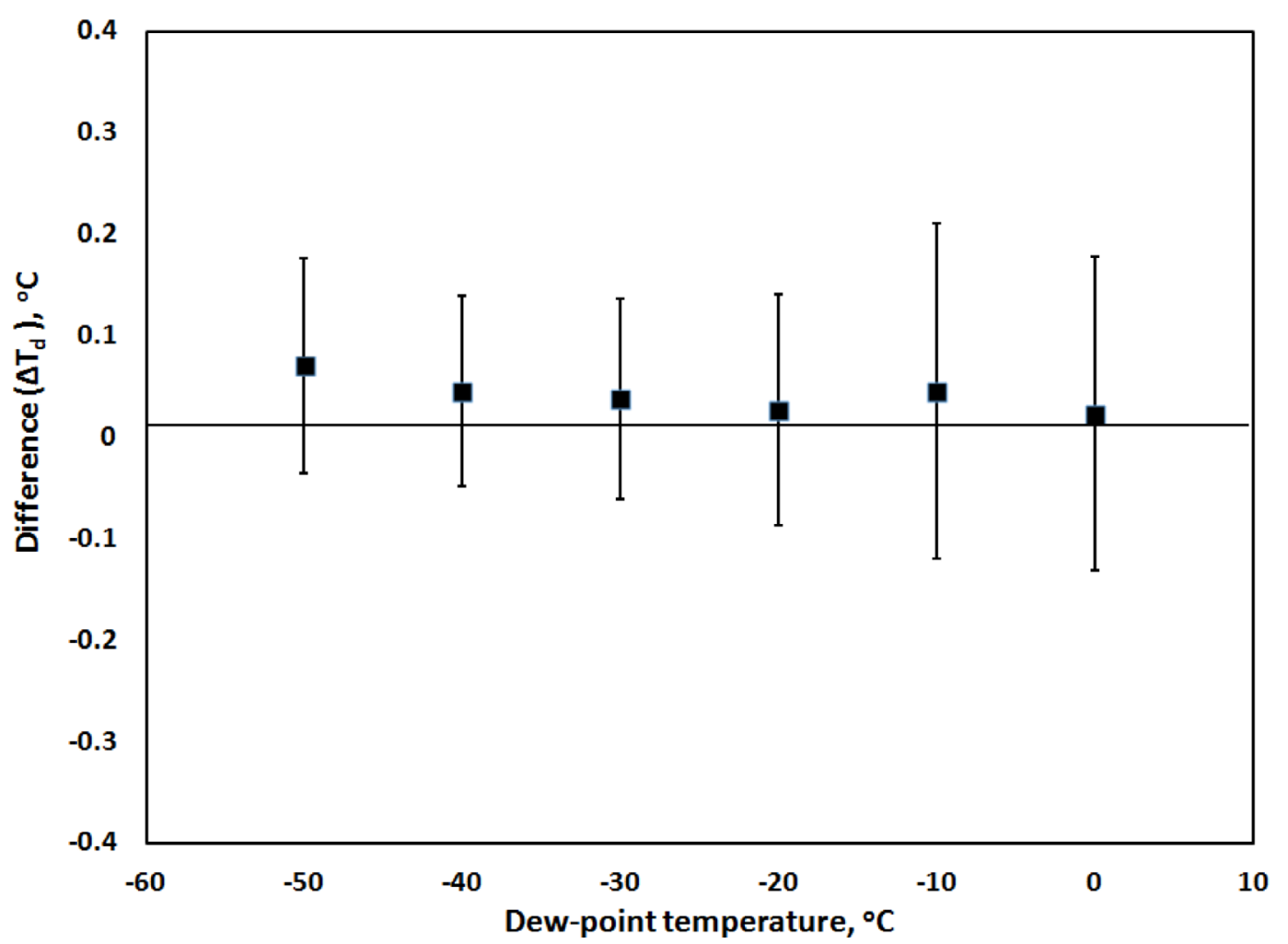

Fig. 3. Differences between the two generators $\left(\Delta T_{\mathrm{d}}=T_{\mathrm{d}(1-\mathrm{T})}-T_{\mathrm{d}(2-\mathrm{T})}\right)$, measured using chilled-mirror hygrometer, with the pair uncertainty $(k=2)$.

of the calibrated chilled-mirror hygrometer. The results are the averages of four runs for each set point in the range from $-50{ }^{\circ} \mathrm{C}$ to $0^{\circ} \mathrm{C}$ dew-point temperature. The stability time is about $4 \mathrm{~h}$.

There is no evidence of a relevant systematic bias between the two generators. The calibration measurement capabilities (CMCs) for these two generators are between $\pm 0.06{ }^{\circ} \mathrm{C}$ and $\pm 0.15^{\circ} \mathrm{C}$ for the $(1-\mathrm{T})$ generator and between $\pm 0.065^{\circ} \mathrm{C}$ and $\pm 0.0713^{\circ} \mathrm{C}$ for the $(2-\mathrm{T})$ generator at a confidence level of approximately $95 \%[6,7]$.
In the present work, the uncertainty of the differences involves both of each generator. Standard uncertainty for each generator denoted as $u_{i}(k=2)$. Both of these uncertainties were combined in quadrature to determine the overall comparison pair uncertainty, denoted as $u_{\mathrm{p}}$, for each dew-point temperature $T_{\mathrm{d}}$.

The uncertainty budget comprises a composition of the uncertainties of each element in the humidity generator [8-12]. Table 1 shows an example of uncertainty budget at $0{ }^{\circ} \mathrm{C}$ for the two generators. 


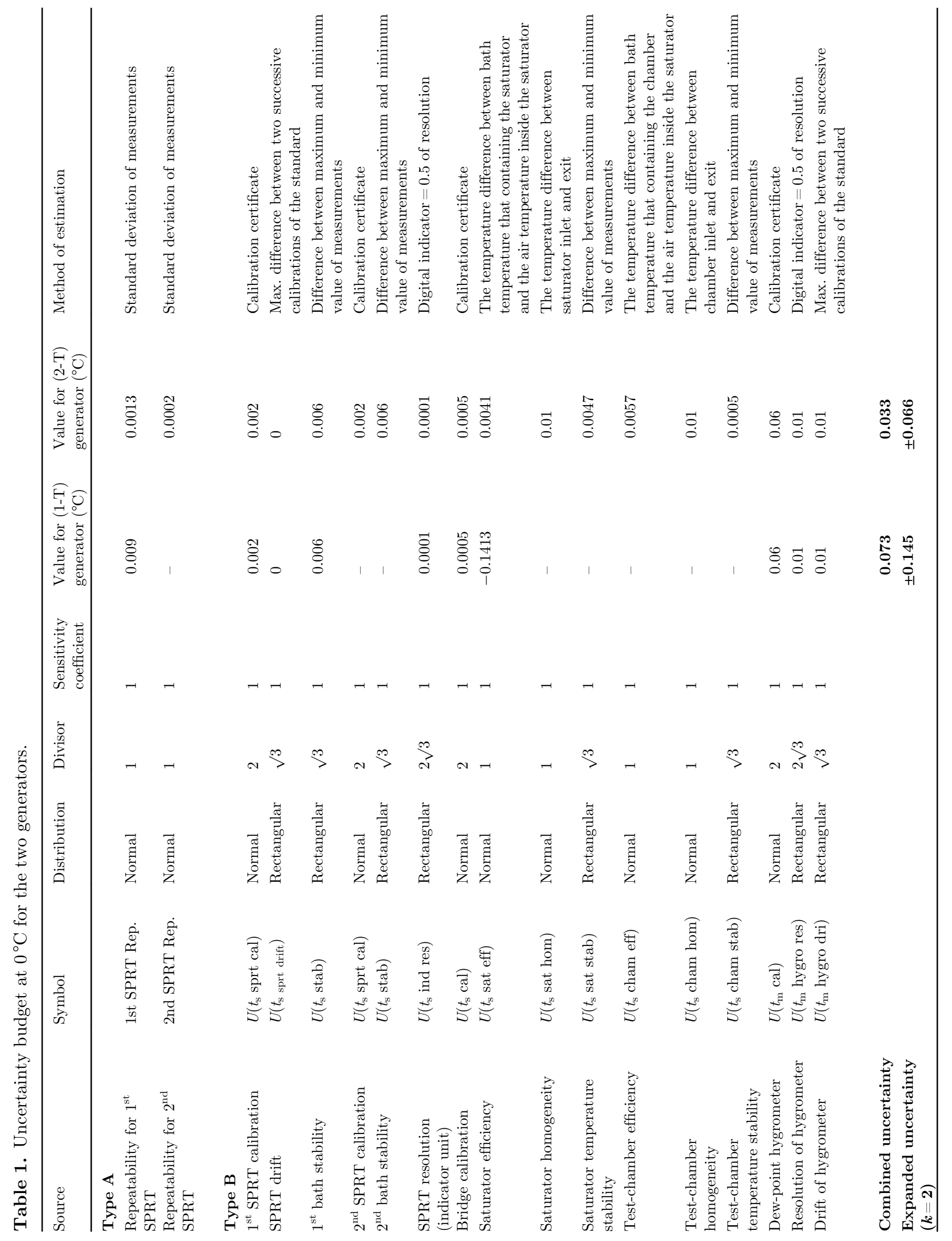


Table 2. The pair uncertainty of NIS two generators.

\begin{tabular}{|c|c|c|c|c|}
\hline $\begin{array}{l}\text { Dew-point } \\
\text { temperature }\end{array}$ & Differences & $\begin{array}{l}\text { Uncertainty } \\
\text { of }(1-\mathrm{T}) \text { generator }\end{array}$ & $\begin{array}{l}\text { Uncertainty of } \\
(2-\mathrm{T}) \text { generator }\end{array}$ & $\begin{array}{l}\text { Pair } \\
\text { uncertainty }\end{array}$ \\
\hline $\begin{array}{l}T_{\mathrm{d}} \\
{ }^{\circ} \mathrm{C}\end{array}$ & $\begin{array}{l}\Delta T_{\mathrm{d}}=T_{\mathrm{d}(1-\mathrm{T})}-T_{\mathrm{d}(2-\mathrm{T})}\left(m_{1}-m_{2}\right) \\
{ }^{\circ} \mathrm{C}\end{array}$ & $\begin{array}{l}U_{(1-\mathrm{T})} \\
{ }^{\circ} \mathrm{C}\end{array}$ & $\begin{array}{l}U_{(2-\mathrm{T})} \\
{ }^{\circ} \mathrm{C}\end{array}$ & $\begin{array}{l}U_{\mathrm{p}} \\
{ }^{\circ} \mathrm{C}\end{array}$ \\
\hline-50.00 & 0.07 & 0.08 & 0.068 & 0.105 \\
\hline-40.00 & 0.045 & 0.06 & 0.071 & 0.093 \\
\hline-30.00 & 0.037 & 0.07 & 0.069 & 0.098 \\
\hline-20.00 & 0.026 & 0.09 & 0.070 & 0.114 \\
\hline-10.00 & 0.045 & 0.15 & 0.069 & 0.165 \\
\hline 0.00 & 0.022 & 0.15 & 0.066 & 0.163 \\
\hline
\end{tabular}

There are two approaches to estimate the uncertainty: 'Type A' and 'Type B' evaluations.

- Type A evaluations: uncertainty estimates using statistical analysis of series of observations (usually from repeated readings)

- Type B evaluations: uncertainty estimates from any other information by means other than the statistical analysis of series of observations. This could be information from past experience of the measurements, from calibration certificates, Manufacturer's specifications, from calculations, from published information. There is a temptation to think of 'Type A' as 'random' and 'Type B' as 'systematic', but this is not necessarily true. The uncertainty budget comprises a composition of the uncertainties of each element and the method of estimation for each element.

As defined by the Mutual Recognition Arrangement (MRA) [13], the degree of equivalence between two measurements (each consisting of a measured value $m_{\mathrm{i}}$ and its uncertainty $u_{\mathrm{i}}$ ) is expressed by the difference between the measured values, $m_{1}-m_{2}$, and the expanded pair uncertainty of this difference $U_{\mathrm{p}}$.

In the present work, the measured difference between the two generators $\Delta T_{\mathrm{d}}$, with the pair uncertainty $(k=2)$, represent the degree of equivalence and the level of consistency for NIS generators with a pair uncertainty given as [1]:

$$
u_{p}=\sqrt{\left(u_{(1-T)}\right)^{2}+\left(u_{(2-T)}\right)^{2}}
$$

or

$$
U_{\mathrm{p}}=\sqrt{\left(U_{(1-\mathrm{T})}\right)^{2}+\left(U_{(2-\mathrm{T})}\right)^{2}}
$$

where $u_{(1-T)}$ and $u_{(2-\mathrm{T})}$ represent the combined standard uncertainties for the (1-T) and (2-T) generators respectively. Similarly, $U_{(1-T)}$ and $U_{(2-T)}$ are the expanded uncertainties.

Thus, the expanded pair uncertainty, $U_{\mathrm{p}}(k=2)$, is $2 u_{\mathrm{p}}$. The results of the comparison are summarized in Table 2. The figure shows that the maximum difference of $-0.07^{\circ} \mathrm{C}$ was found at $-50^{\circ} \mathrm{C}$, which is near $-60^{\circ} \mathrm{C}$, the limit of the working range of the chilled-mirror hygrometer. Also it was noted that the difference at $-10^{\circ} \mathrm{C}$ is different from the differences at $-20^{\circ} \mathrm{C}$ and $0{ }^{\circ} \mathrm{C}$. This was also noted previously $[8,9]$ and thus confirms the reproducibility of each generator. These differences have no evidences of relevant systematic bias between the two generators.

\section{Conclusion}

A comparison of the two standard humidity generators used for the national realization of dew-point temperature at the National Institute for Standards (NIS), has shown their consistency in the range from $-50^{\circ} \mathrm{C}$ to $0{ }^{\circ} \mathrm{C}$, within the reproducibility of the transfer standard. The differences found were from $0.02{ }^{\circ} \mathrm{C}$ and $0.07^{\circ} \mathrm{C}$ along the concerned range. They are insignificant compared to the generators uncertainties. These values agreed within the expanded pair uncertainties that ranged from $\pm 0.09^{\circ} \mathrm{C}$ and $\pm 0.15^{\circ} \mathrm{C}$.

The results ensure that the calibration history and, in particular, the record of the long-term stability of the transfer standard is maintained.

In addition, this comparison showed also that for customers that are obtaining their traceability from either of the two generators or who have subsequent calibrations using different generators will not observe any systematic difference due to the reference dew-point generator.

\section{References}

1. M.G. Ahmed, Y. Hermier, Degree of equivalence of realizations of the triple points of argon and oxygen between NIS and LNECnam, Int. J. Thermophys. 35(3), 596-603 (2014)

2. D. Zvizdic, V. Kolobaric, I. Galaso, D. Serfezi, A new two temperature humidity generator as a primary standard for measuring humidity in Croatia, in Proceedings $I$ of the TEMPMEKO-99, The 7th International Symposium on Temperature and Thermal Measurements (1999), pp. 203-208

3. H.G. Liedberg, M.R. Mnguni, D. Jonker, A simple humidity generator for relative humidity calibrations, Int. J. Thermophys. 29, 1660-1667 (2008) (Springer Science Business Media)

4. D. Hudoklin, J. Drnovšek, The New LMK Primary Standard for dew-point sensor calibration: evaluation of the high-range saturator efficiency, Int. J. Thermophys. 29(5), 1652-1659 (2008) (Springer Science Business Media) 
5. R. Benyon, T. Vicente, Consistency of the national realization of dew-point temperature using standard humidity generators, Int. J. Thermophys. 33(18), 1550-1558 (2012)

6. M.G. Ahmed, S. Mazen, D.A. El-Gelil, Development of NIS two-temperature humidity generator, J. Phys. Sci. Appl. 4 (7), 436-439 (2014)

7. D.A. El-Gelil, M.G. Ahmed, E.E.-D. Mahmoud, S. Mazen, in Proceeding of World Congress, Metrology for Green Growth (XX IMEKO 2012), 9-14, Busan, Republic of Korea (2012)

8. K. Chahine, Calculation of uncertainty in humidity measurement using chilled mirrors and temperature sensors, Valuing Metrology, Victoria, Australia (Metrology Society of Australia, 2004)

9. F.M. Megahed, Y.A. Abdelaziz, Uncertainty evaluation in the calibration of $\mathrm{Pt} / \mathrm{Pd}$ thermocouples up to copper freezing point at NIS-Egypt, Int. J. Metrol. Qual. Eng. 2(24), 13-17 (2011)
10. ISO/IEC Guide 98-3:2008, uncertainty of measurement part 3: guide to the expression of uncertainty in measurement (GUM, 1995)

11. D. Hudoklin, J. Setina, J. Drnovšek, Uncertainty evaluation of the new setup for measurement of water vapor permeation rate by a dew-point sensor, Int. J. Thermophys. 33, 1595-1605 (2012), DOI:10.1007/s10765-0121213-1

12. J. Nielsen, M.J. de Groot, Revision and uncertainty evaluation of a primary dew-point generator, Metrologia 41(3), 167-172 (2004)

13. Comité International des Poids et Mesures, Mutual Recognition of National Measurement Standards and of Calibration and Measurement Certificates Issued by National Metrology Institutes (Bureau International des Poids et Mesures (BIPM), Sèvres Cedex, Paris, 1999)

Cite this article as: Doaa Abd El-Galil, Mohamed Gamal Ahmed, Consistency of the national realization of dew-point temperature using NIS standard humidity generators, Int. J. Metrol. Qual. Eng. 8, 1 (2017) 